Check for updates

1 Department of Health Policy, London School of Economics, London, UK

2 Department of International Health and O'Neill Institute for National and Global Health Law, Georgetown University, Washington, DC, USA

3 Fundacion Octaedro, Quito, Ecuador

4 Center for Policy Impact in Global Health, Duke Global Health Institute, Duke University, Durham, NC, USA

Correspondence to: G Yamey gavin.yamey@duke.edu

Cite this as: BMJ2021;373:n1295 http://dx.doi.org/10.1136/bmj.n1295 Published: 21 May 2021

\section{Preparing for the next pandemic}

\section{The recommendations of the Independent Panel for Pandemic Preparedness and Response do not go far enough}

\author{
Clare Wenham, ${ }^{1}$ Matthew Kavanagh, ${ }^{2}$ Irene Torres, ${ }^{3}$ Gavin Yamey ${ }^{4}$
}

"Make it the last pandemic," urges the report of the Independent Panel for Pandemic Preparedness and Response, convened by the World Health Organization to assess the handling of covid-19. ${ }^{1}$ The report highlights how several governments and international organisations did too little to mitigate covid-19. It proposes a plan to end this pandemic-what it calls "the 21st century's Chernobyl moment"-and prevent another one.

The panel makes six recommendations. Governments must urgently provide oxygen, diagnostics, and vaccines equitably worldwide to halt the spread of SARS-CoV-2. All nations must strengthen their capacity to prevent, detect, and respond to pandemics. A high level global council on health threats should be established for political attention and allocation of pandemic funds. Countries should adopt a new, legally binding pandemic treaty. A global platform should be built for equitable development and distribution of drugs, vaccines, and medical supplies. And WHO should get more power and money.

These are good recommendations. But we need bigger reform. The problem is one of government compliance. States gave WHO the mandate to lead any response to emerging epidemics within the International Health Regulations (IHR). Embracing these regulations, on 23 January 2020, WHO told all nations to prepare for covid-19 and deploy rapid diagnosis, tracing, isolation, and quarantine. ${ }^{2}$ On 30 January 2020, it declared a public health emergency of international concern, the highest clarion call for global health security. ${ }^{3}$ Yet many countries ignored WHO advice, focused on nationalistic approaches, and rejected norms of global solidarity.

Rich nations continue to reject such norms, hoarding doses of covid-19 vaccines and blocking poorer nations from local production. ${ }^{4}$ It is therefore ironic that many of the same governments that rejected WHO advice and embraced vaccine nationalism are pushing hardest for a pandemic treaty. ${ }^{5}$

\section{Lack of teeth}

Under this treaty, governments would offer political commitment to the IHR and agree to legally enshrined solidarity to prevent and mitigate future outbreaks. It is intended to add political impetus to the legal requirements for future leaders to put global health security ahead of national interest. Yet leaders have failed to comply with international legal obligations under IHR in the past 16 months, so why would they behave differently in a future pandemic just because of a treaty? ${ }^{6}$ For this treaty to have teeth, it needs either meaningful sanctions for non-compliance, which seems politically unsellable, or some incentive for compliance, such as financing tied to reporting outbreaks and duly sharing information.

The panel proposes the creation of a new international pandemic financing facility with contributions of $\$ 5 \mathrm{bn}-\$ 1 \mathrm{obn}(£ 3.5 \mathrm{bn}-\mathrm{f} 7 \mathrm{bn}$; $€ 4 \mathrm{bn}-€ 8 \mathrm{bn})$ annually, to finance both ongoing preparedness and emergency response. This would be distinct from the World Bank's Pandemic Emergency Financing Facility, which the bank has now abandoned. ${ }^{7}$ Wealthier nations would pay the most. Yet governments have previously failed to voluntarily fund preparedness. For example, in 2019 WHO was unable to secure $\$ 100 m$ to fund its contingency fund for emergencies fully. ${ }^{8}$ For a future pandemic financing facility to succeed, a mandatory mechanism is needed. ${ }^{9}$

Moreover, the distribution of such funds should not be at the discretion of a global council on health threats. It should be tied to reporting under IHR, incentivising compliance. Suggestions to support national coordination and outbreak response capacities must consider the financial and sociopolitical realities (or nuances) of individual countries.

A threats council could be valuable if it tackled non-compliance by forcing heads of state to take responsibility. But it would need powers and governance more akin to the UN Security Council than current global health structures unable to curb powerful states. Without care, it could take remaining political power from WHO, further weakening the institution that the panel seeks to strengthen as the lead coordinator for global health emergencies. But the panel's suggestion to assess preparedness through the powerful International Monetary Fund, which lacks health expertise and has policies that often undermine public health, ${ }^{10}{ }^{11}$ would better be scrapped in favour of giving WHO more leverage.

The panel recommends that the Access to Covid-19 Tools Accelerator, launched 13 months ago to speed development and equitable access to tools for controlling covid-19, should be made permanent with representative governance. But equitable access to vaccines and diagnostics has not been secured, with lower income countries locked out as rich countries used their power to put their entire populations at the front of the queue ahead of the most vulnerable globally. Monopolies on knowledge and production meant a handful of companies, not public health entities, allocated doses globally..$^{12}$ Making the accelerator permanent is unlikely to solve these problems, which demand fundamentally different power and knowledge structures. 


\section{Ways forward}

Global leaders should do even more while the window for change is open. "If not now, then when?" says the panel. We agree. Emergency funding should be tied to the declaration of a public health emergency of international concern-from mandatory contributions that are sufficient to enable rapid response. This would avoid the problems seen with the World Bank's pandemic emergency financing facility, whose payment rules were so narrow that countries sometimes failed to receive payments during outbreaks. ${ }^{13}$ The panel proposes an automatic waiver of World Trade Organization rules on intellectual property over covid-19 tools if companies do not volunteer to share know-how in three months from now-but why wait three months? In the future this waiver could be made automatic whenever there is an international public health emergency. If a treaty is to be written, there should be a way to enforce it-even if only through mandatory reporting. Giving global health governance and WHO sufficient political power and financing is the only way to end to the cycles of panic and neglect we continue to experience worldwide.

Competing interests: We have read and understood BMJ policy on declaration of interests and declare the following: GY is a signatory to the People's Vaccine campaign. He was a member of the Covid-19 Vaccine Development Taskforce, hosted by the World Bank, and participated as an unpaid academic adviser in the consultation process that led to the launch of Covax, the global pooled covid-19 vaccine allocation mechanism. He has received grant funding from WHO; Gavi, the Vaccine Alliance; and the Bill and Melinda Gates Foundation.

Provenance and peer review: Not commissioned; not externally peer reviewed.

1 Independent Panel for Pandemic Preparedness and Response. Covid-19. Make it the last pandemic 2021. https://theindependentpanel.org/wp-content/uploads/2021/05/COVID-19-Make-it-theLast-Pandemic_final.pdf

2 WHO. Statement on the first meeting of the International Health Regulations (2005) Emergency Committee regarding the outbreak of novel coronavirus (2019-nCoV). 23 Jan 2020.

https://www.who.int/news/item/23-01-2020-statement-on-the-meeting-of-the-internationalhealth-regulations-(2005)-emergency-committee-regarding-the-outbreak-of-novel-coronavirus(2019-ncov)

3 WHO. Statement on the second meeting of the International Health Regulations (2005) Emergency Committee regarding the outbreak of novel coronavirus (2019-nCoV). 30 Jan 2020.

https://www.who.int/news/item/30-01-2020-statement-on-the-second-meeting-of-the-international-health-regulations-(2005)-emergency-committee-regarding-the-outbreak-of-novel-coronavirus-(2019-ncov)

4 Gonsalves G, Yamey G. The covid-19 patent waiver: a crucial step towards a "people's vaccine." BMJ Opinion, 10 May 2021. https://blogs.bmj.com/bmj/2021/05/10/the-covid-19-vaccine-patentwaiver-a-crucial-step-towards-a-peoples-vaccine/

5 Third World Network. WHO: should members pursue a pandemic treaty in the midst of a global pandemic? 2021. https://www.twn.my/title2/health.info/2021/hi210507.htm

6 Wenham C. A global pandemic treaty won't work until leaders realise the benefits of solidarity. Guardian2021 Apr 1. https://www.theguardian.com/commentisfree/2021/apr/01/global-pandemictreaty-covid-disease-control

7 World Bank abandons pandemic bond instrument after disastrous Covid-19 response. Brettonwoods Project, 6 Oct 2020. https://www.brettonwoodsproject.org/2020/10/world-bankabandons-pandemic-bond-instrument-after-disastrous-covid-19-response/

8 Independent Oversight and Advisory Committee for the WHO Health Emergencies Programme. Looking back to move forward. 2020. https://apps.who.int/gb/ebwha/pdf_files/WHA73/A73_10en.pdf

9 Yamey G, Jamison D, Hanssen O, Soucat A. Financing global common goods for health: when the world is a country. Health Syst Reform 2019;5:334-49. doi: 10.1080/23288604.2019.1663118 pmid: 31860402

10 Stuckler D, Basu S. The International Monetary Fund's effects on global health: before and after the 2008 financial crisis. Int J Health Serv2009;39:771-81. doi: 10.2190/HS.39.4.j pmid: 19927414

11 Stubbs T, Kentikelenis A, Stuckler D, McKee M, King L. The impact of IMF conditionality on government health expenditure: a cross-national analysis of 16 west African nations. Soc Sci Med 2017;174:220-7.doi: 10.1016/j.socscimed.2016.12.016 pmid: 28087084

12 Kavanagh MM, Pillinger M, Singh R, Ginsbach K. To democratize vaccine access, democratize production. Foreign Policy 2020 Mar 1. https://foreignpolicy.com/2021/03/01/to-democratizevaccine-access-democratize-production/

13 Brim B, Wenham C. Pandemic Emergency Financing Facility: struggling to deliver on its innovative promise. BMJ2019;367:15719. doi: 10.1136/bmj.l5719 pmid: 31597630
This article is made freely available for use in accordance with BMJ's website terms and conditions for the duration of the covid-19 pandemic or until otherwise determined by BMJ. You may use, download and print the article for any lawful, non-commercial purpose (including text and data mining) provided that all copyright notices and trade marks are retained. 